\title{
Preface to the special issue
} NMR of Polymers: recent advances and innovations

Polymer Journal (2012) 44, 733; doi:10.1038/pj.2012.139

$\mathrm{W}$ e are pleased to present the August issue of the Polymer Journal as a special issue entitled 'NMR of Polymers: recent advances and innovations'. This special issue is part of the celebrations to mark the 30th anniversary of the Research Group on Nuclear Magnetic Resonance (RGNMR), a subsidiary group of the Society of Polymer Science, Japan (SPSJ). The RGNMR was formed in October 1980 to promote communication amongst the members of the SPSJ who were incorporating NMR studies in their research. The first symposium was held on the 31st May, 1981 in Kyoto. Dr Riichiro Chujo (Professor Emeritus of Tokyo Institute of Technology) served as the first Chairperson (1981-1983). Since then, the group has been growing, actively playing its role as a forum for interactive communication among its members and also as a training facility for young polymer scientists. The fact that the number of memberships has risen to 106 (including 17 corporate members) over the last 30 years suggests that the activities of the RGNMR have been useful and well received by members, and NMR spectroscopy as an analytical tool and method continues to gain significance in the polymer research field.

The main activities of the RGNMR are the symposia held in the spring and autumn of each year. Each symposium will feature a different topic of current interest, where leading researchers are invited to present a talk describing their latest research on these themes. These symposia are useful to bring people with common research interests together, give them a chance to receive an update on the latest research in the field and then generate active co-operation and communication among the members. From 2000, we started to run poster sessions in conjunction with the spring meetings, and then in 2010, the young poster award was established. These turned out to be very useful, especially for the young members who were able to get to know other members of the society and discuss problems and exchange ideas pertaining to their research interests. In addition to the basic NMR study sessions organized for the young NMR scientists, which the RGNMR has been facilitating since 1989, we aim to continue to further develop activities that will encourage and benefit our younger members.

Recently, the 30th anniversary symposium ' 30 years of NMR of polymers: course of progress and challenges for future' was held in Tokyo on the $8-9$ th December, 2011. The symposium began with commemorative speeches by four of the former chairpersons of the RGNMR: Riichiro Chujo, Isao Ando (5th Chairperson; 1990-1991, Professor Emeritus, Tokyo Institute of Technology), Fumitaka Horii (7th Chairperson; 1994-1995, Professor Emeritus, Kyoto University), and Tetsuo Asakura (10th Chairperson; 2000-2001), followed by invited lectures on various topics in NMR by 10 distinguished speakers, including Dr Qun Chen, Vice President of East China Normal University, and Professor Kay Saalwächter of Martin-Luther University. In addition, a total of 33 posters were presented at the accompanying poster session. We are very pleased that the anniversary symposium was a great success.

At the end of the anniversary year, we decided to publish a specially-edited issue of the Polymer Journal to mark this occasion. This special issue is designed not only to feature the past achievements of the RGNMR but also to emphasize the active roles and important contributions of NMR in today's polymer studies. The special issue consists of 25 papers contributed by the members of RGNMR that will give readers an idea of how active our members utilize NMR in a wide-variety of research areas within polymer science, such as semi-crystalline polymers, blends and rubbers, biopolymers and peptides, statistical investigations, permeability and dissolution of gasses in polymers, structural determination of polymers and supramolecules, and methodology and new applications. We are also fortunate that we could include two specially-invited contributions from Professors Kay Saalwächter and Isao Ando, as the highlight articles of this anniversary issue.

We would like to thank all who kindly contributed their papers for this issue and the editors of Polymer Journal for their kind help and co-operation. We are also indebted to the Polymer Journal editorial office at SPSJ and the publishing and production teams at Nature Publishing Group for their assistance in preparation and publication of this issue.

Tetsuo Asakura ${ }^{1}$ and Atsushi Asano ${ }^{2}$ Guest Editors

${ }^{1}$ Department of Biotechnology, Tokyo University of Agriculture and Technology, Koganei, Japan and ${ }^{2}$ Department of Applied Chemistry, National Defense Academy, Yokosuka, Japan E-mail: asakura@cc.tuat.ac.jp and asanoa@nda.ac.jp 